\title{
Insatiable Narcissism Underlying Addictive Behavior: Outline of a Biosystematic Model
}

\author{
Bernhard J. Mitterauer \\ Volitronics-Institute for Basic Research and Psychopathology, Wals, University of Salzburg, Salzburg, Austria \\ Email: mitterauer.b@gmail.com
}

How to cite this paper: Mitterauer, B.J. (2021) Insatiable Narcissism Underlying Addictive Behavior: Outline of a Biosystematic Model. Open Journal of Medical Psychology, 10, 61-69.

https://doi.org/10.4236/ojmp.2021.104006

Received: July 6, 2021

Accepted: August 16, 2021

Published: August 19, 2021

Copyright $\odot 2021$ by author(s) and Scientific Research Publishing Inc. This work is licensed under the Creative Commons Attribution International License (CC BY 4.0).

http://creativecommons.org/licenses/by/4.0/

(c) (i) Open Access

\begin{abstract}
This study is a contribution to basic research on narcissism shown on addictive behavior. A new biosystematic model of narcissism underlying addictive behavior is outlined. Basically, normal narcissism is defined as the self-reference of living systems maintaining their circular organization and identity. The communication between narcissistic systems follows the narcissistic logic of fitting or non-fitting of structures (a third possibility is excluded) shown on geometric diagrams. From this model of narcissistic interactions with the environment, addictive behavior is deduced. If the narcissistic desire for the ideal objects cannot be satisfied in the environment, the narcissist attempts to cope with this lack of intended objects by abuse of addictive substances. This leads to an overexpression of receptors in pertinent brain areas that may underly craving on the behavioral level, interpreted as pseudo satisfaction of narcissistic desires-destiny becomes an addiction. In conclusion, the significance of the biosystematic model of narcissism for the understanding of addictive communication and the psychopathology of depression is briefly discussed.
\end{abstract}

\section{Keywords}

Narcissism, Logic of Narcissism, Pseudosatisfaction, Addiction

\section{Introduction}

The concept of narcissism introduced by Freud [1] has been further developed by the psychoanalysts Kohut [2] and Kernberg [3] and psychologists most notably Millon [4] leading to the introduction of the diagnostic concept of the narcissistic personality disorder [5]. Current understanding of narcissism and narcissistic personality disorder is excellently reviewed by Yakeley [6]. The narcissistic personality disorder is characterized by personality traits of grandiosity 
and attention-seeking and significant impairments of personality functioning (e.g. perceive oneself as exceptional, persistent fantasies of success, looking excessively to others for the regulation of self-esteem [7]. Moreover, the narcissistic spectrum model integrates existing theories of narcissism characterizing narcissistic personality by self-importance, grandiosity and vulnerability [8].

Significantly, the basic criteria for substance use disorder [7] suggest parallels between narcissism and drug abuse (cravings to use the substance and tolerance) [9]. Similarly, Rogier and Velotti [10] found that gambling disorder is associated with grandiose narcissism and inability to regulate emotion, but not with vulnerable narcissism. Based on a literature review Laurence defined "narcissism as addiction to esteem, and addiction as a narcissistic pursuit" [11].

From an interdisciplinary, system-oriented point of view narcissism can be defined as organismic self-reference [12]. This concept has been further elaborated [13] [14] and introduced in my models of the psychopathology of mental or affective disorders [15] [16] [17]. The present paper outlines an elementary biosystematic model of narcissistic self-reference and communication, from which addictive behavior in the sense of insatiable narcissism can be deduced.

\section{Elementary Architecture and Function of Narcissism}

\subsection{Narcissistic Self-Reference and Communication}

Abstract formulated narcissism is total self-reference [12]. According to C.G. Jung self-reference represents an archetypic system comparable to a snake biting in its own tail, called Ouroboros [18]. Let us suppose that any living system forms a virtual cycle that exists in an empty space and is only equipped with self-movement (Figure 1).

Suddenly, another self-cycling living system enters into the space so that the problem of communication arises (Figure 2). Since both living systems are self-referring systems, they obey the all-or-none logic of narcissism. Therefore, communication can only be realized, if one living system becomes incorporated by the other and vice versa. However, for the process of incorporation both virtual living systems (Figure 2) must be self-embodied with material.

Basically, for the distinction between the narcissistic systems each system must be endowed with a specific composition of material (Figure 3).

Since some structures of both systems are equal and others differ, the narcissistic all-or-none logic works on a mechanism of fitting or non-fitting (a third possibility is excluded). To realize these operations an evolutive process is necessary, in which the original cycle evolves to a sphere with many places of specific compositions (shown in Figure 3 as geometric forms). In parallel, numerous living systems and objects in the environment evolve. In this situation, the original solitary narcissistic system is faced with the problem of communicating in a poly-ontological (consisting of many loci) world [13] [19] [20].

Figure 3 gives a simple example of self embodiment of two narcissistic systems $(\mathrm{x}, \mathrm{y})$ in the world of objects according to the logic of fitting or non-fitting. 


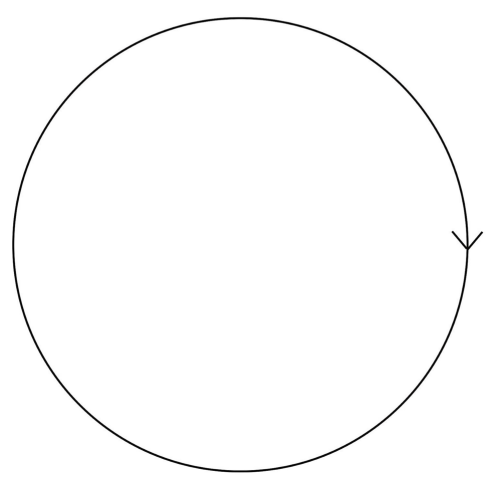

Figure 1. Virtual narcissistic self-referring system depicted as a self-rotating cycle.

narcissistic system $x$

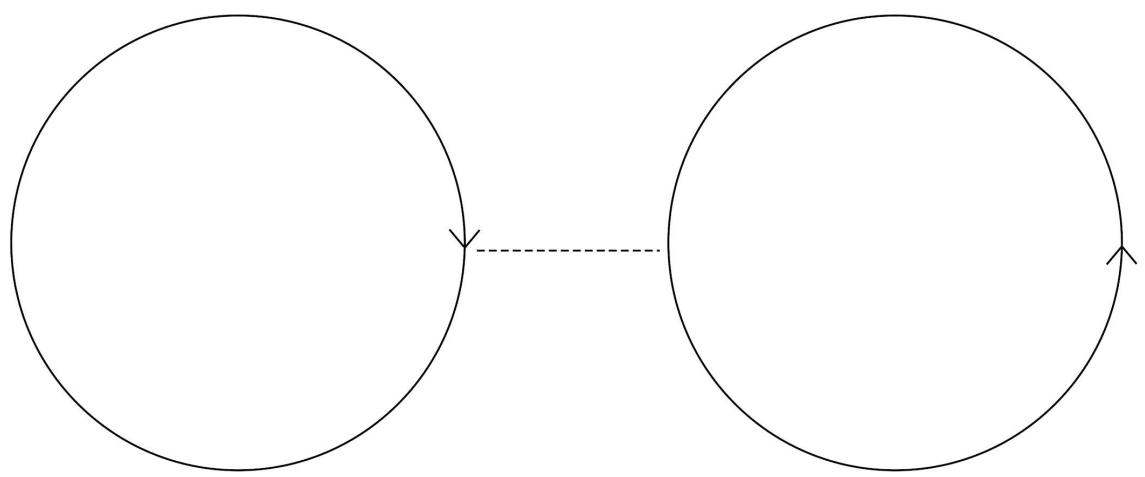

Figure 2. Two narcissistic self-referring systems (x,y): the problem of communication arises (dotted line).
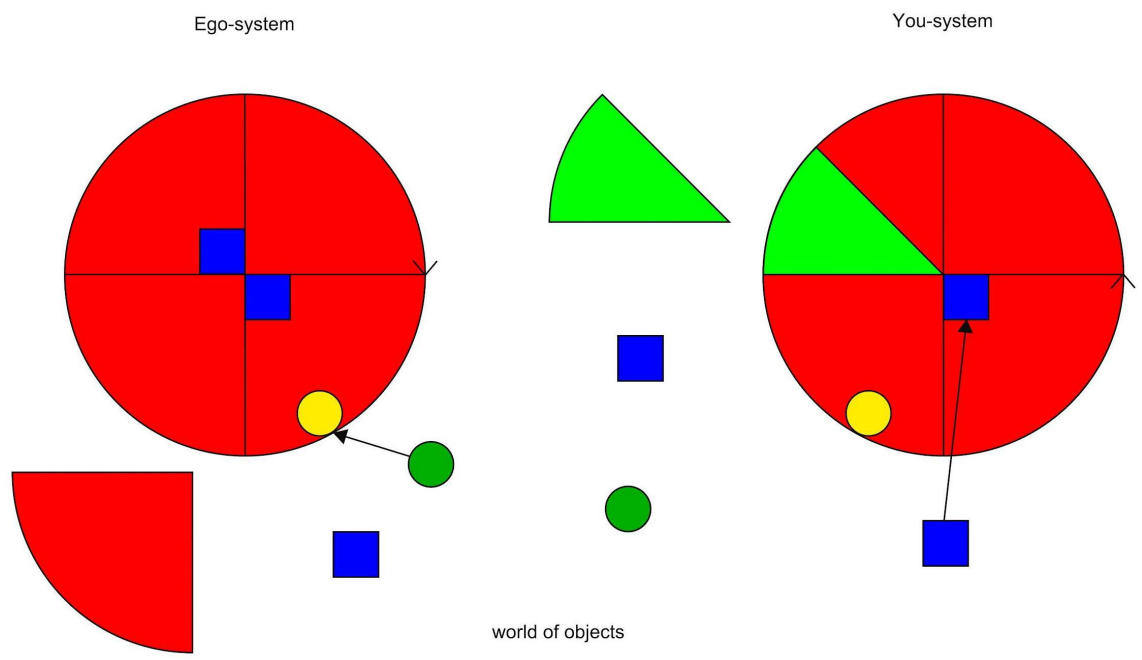

Figure 3. Self embodiment of the narcissistic Ego-system and You-system in the world of objects according to the logic of fitting or non-fitting. Both systems are composed of the same geometric figures in different distribution. All objects in the environment correspond to the geometric figures of both systems. Two examples of incorporation of suitable objects of the environment are shown (arrows). 
Although the geometric composition of the two systems differs, they correspond to all objects in the environment. In this figure, two examples of incorporation of objects into the environment are depicted.

\subsection{Narcissistic Desire}

Based on the key-lock principle living systems either accept objects or reject them with the intention to realize their desires [21]. However, normal narcissism, capable of communicating, comes to existential limits, if the environment lacks appropriate objects or a specific object cannot be found. A person in that situation feels out of place since his (her) desires cannot be fulfilled. We observed that these narcissistic personalities are at risk of committing suicide intending a radical "change of the place of existence" [22] towards an "appropriate" world (paradise). But depression or (and) addictive behavior mostly occur as abnormal coping strategies. Most importantly, such existential crises are basically caused by the aggravation of the narcissistic logic of fitting or non-fitting, since not only an appropriate structure (e.g. a sphere of any material), but also a suitable specific material ("the sphere must be golden") is absolutely intended. Figure 4 shows a graphic of the narcissistic desire for the "golden sphere" which does not exist in the environment. This drawing focuses on the many-places composition (different geometric figures) of the narcissistic Ego-system and the various objects in the environment. Note that all corresponding places of which the Ego-system is composed, exist in the environment, only the golden sphere cannot be found in the environment (yellow circle).

\section{Pseudosatisfaction of the Narcissistic Desire in Addictive Behavior}

Ultimately, the narcissistic Ego experiences that indeed spheres, suitable for
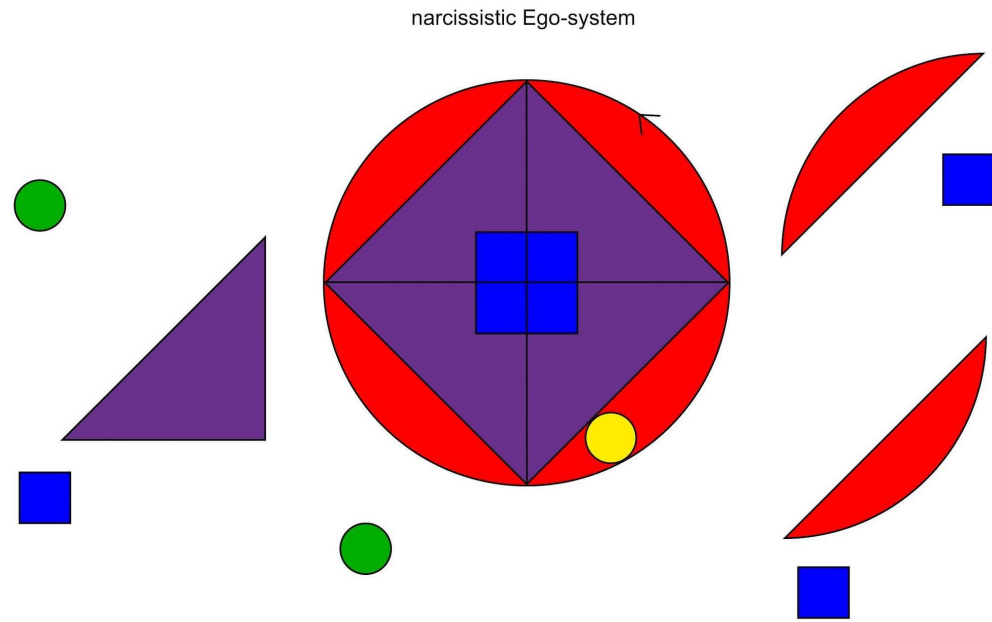

world of objects

Figure 4. Narcissistic desire to the "golden sphere" not to be found in the environment. All geometric figures of the Ego-system exist in the world of objects except the desired "golden sphere" (yellow circle). 
satisfaction of these places of desire is available in the environment (Figure 5). This means that non-golden spheres also fit in the "synaptic lock" imitating a golden sphere. Importantly, the experience of the seeming existence of the desired objects causes euphoria. However, sooner or later the narcissistic Ego realizes that the spheres are not golden. Disappointment and depression are the consequence.

To cope with this painful situation and to stay alive, the organization of the place structure of the narcissistic ego transforms by an increased generation of "sphere-places" (Figure 6). In this process, the quality of golden spheres is compensated by the quantity of non-golden spheres. An addictive hunt for euphoria

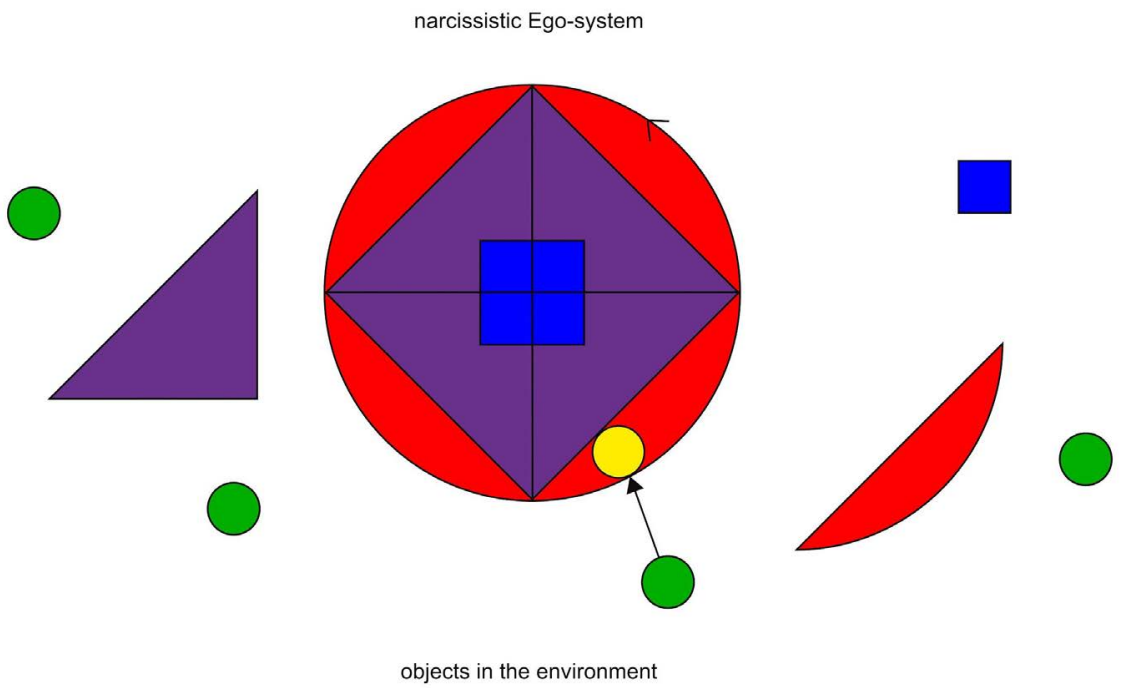

Figure 5. "Non-golden" spheres (green circles) fit in the "synaptic" lock imitating golden spheres. A green circle becomes incorporated (arrow) in the yellow circle.

narcissistic Ego-system

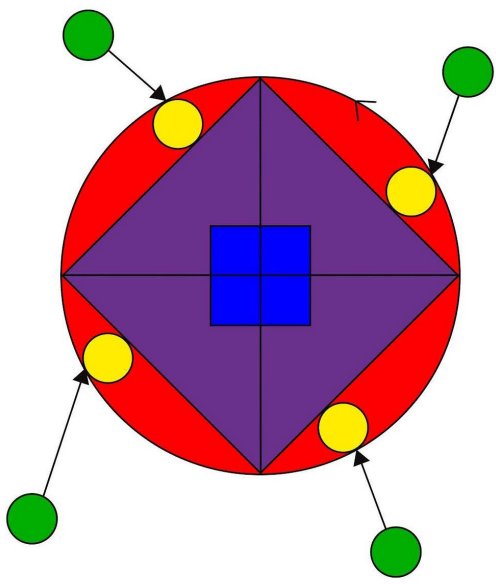

world of addictive substances

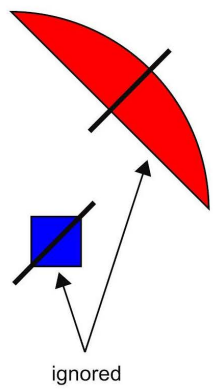

objects in the environment

Figure 6. Increase of "sphere-places" for pseudo satisfaction of the narcissistic desire. All green circles become incorporated (arrows) in the yellow circles. Other objects of the environment are ignored (strong black lines). 
begins and never ends. In parallel, other types of objects, normally accepted in communication, become rejected. In this fashion, the communication of the addictive narcissistic personality increasingly narrows down to addictive substances. In essence, the spread out of "sphere-places" in the bio systemic model here outlined represents a pseudo satisfaction of the narcissistic desire-destiny becomes addiction.

Whereas a narcissistic person with depression experiences specific or even all domains of reality as inappropriate for the realization of his (her) desires, the addicted narcissist strives for substances, which imitate an appropriate environment. Indeed, these substances fit in the synaptic lock of the material equipment of his (her) brain but cause imbalances of glial-neuronal interactions in tripartite synapses of the brain. The brain reacts with an overproduction of receptors that are suitable for activation by addictive substances [23], but exert no constructive effects since addictive substances do not embody objects of the environment that are really intended by the narcissistic desire.

Basically, the increase of the number of receptors "craves satisfaction" by occupancy with addictive substances. This is the diabolic cycle of addictive behavior responsible for substance tolerance, loss of control and dependence [7]. In other words: the addicted narcissist lives in an illusionary world in danger of perishing from insatiability.

\section{Discussion and Conclusions}

The significance of the biosystematic model of narcissism here proposed lies in the description of elementary structures on which normal and pathological narcissism operate. In general terms, narcissism is total self-reference formally described as a permanent rotating cycle. Maturana characterized living systems as self-referring systems circularly organized to maintain their identity [20]. Here we speak of a normal narcissistic organization [12] [13]. Note that the interactions of a narcissistic system with the environment (objects, subjects) follow exclusively the narcissistic logic of fitting or non-fitting structures shown on diagrams of geometric figures. Therefore, narcissistic systems either accept or reject objects of the environment to realize their desires [21]. This is the rationale of the model proposed that may underly the phenomenology of narcissism.

From this model of narcissistic interactions with objects of the environment, addictive behavior can be deduced. If narcissistic desire cannot be satisfied in the environment by intended objects, the narcissistic person tries to cope with the lack of intended objects by abuse of addictive substances. Though the ideal objects ("golden spheres") cannot be found in the environment, "non-golden spheres" also fit in the receptor structures of the brain generating euphoria.

The relevance of neuroscience for the investigation of narcissism is reviewed by Di Samo and coworkers focusing on personality neuroscience for the development of a more complete view of narcissism [24]. Experimental investigations indicate upregulation of opioid receptors in response to repeated exposure to 
cocaine and ethanol, and the resulting opioid receptor upregulation may play an important role in craving [23]. Similarly, chronic nicotine abuse also upregulates nicotinic acetylcholine receptors throughout the brain and leads to nicotine seeking [25]. Together, the increase of receptors in the brain that may underly craving on the behavioral level can be interpreted as pseudo satisfaction of narcissistic desire so that desire becomes addiction.

Finally, it should be mentioned that the biosystematic model proposed outlines elementary mechanisms of narcissism prone to addictive behavior not only in substance abuse but also in intersubjective communication as in addictive use of social media [26] [27]. Narcissists crave affirmation from others like a physical addiction [11]. Admittedly, one may argue that this model is too abstract lacking the explanatory power of psychodynamic mechanisms. However, the more formal description of narcissism may stimulate basic research on addictive communication and on the psychopathology of depression [16].

\section{Acknowledgements}

I am grateful to Christian Streili for designing figures and Marie Motil for preparing the final version of the paper.

\section{Conflicts of Interest}

The author declares no conflicts of interest regarding the publication of this paper.

\section{References}

[1] Freud, S. (1914) On Narcissism. In: Strachey, J., Ed., The Standard Edition of the Complete Psychological Works of Sigmund Freud, Hogarth Press, London, 67-102.

[2] Kohut, H. (1971) The Analysis of the Self: A Systematic Approach to the Psychoanalytic Treatment of Narcissistic Personality Disorders. International Universities Press, New York.

[3] Kernberg, O.F. (1984) Severe Personality Disorders: Psychotherapeutic Strategies. Yale University Press, New Haven.

[4] Millon, T. (1981) Disorders of Personality. John Wiley and Sons, Hoboken.

[5] American Psychiatric Association (1980) Diagnostic and Statistical Manual of Mental Disorders. 3rd Edition, (DSM-III) American Psychiatric Association, Washington DC.

[6] Yakeley, J. (2018) Current Understanding of Narcissism and Narcissistic Personality Disorder. BJPsych Advances, 24, 305-315. https://doi.org/10.1192/bja.2018.20

[7] American Psychiatric Association (2013) Diagnostic and Statistical Manual of Mental Disorders. 5th Edition, DSM-5, American Psychiatric Association, Washington DC. https://doi.org/10.1176/appi.books.9780890425596

[8] Krizan, Z. and Herlache, A.D. (2017) The Narcissism Spectrum Model: A Synthetic View of Narcissistic Personality. Personality and Social Psychology Review, 22, 3-31. https://doi.org/10.1177/1088868316685018

[9] Salazar, J., Page, B. and Ripoll, C. (2021) Features, State and Context of Narcissism in Drug Misuse. Substance Use and Misuse, 56, 11-24. 
https://doi.org/10.1080/10826084.2020.1833923

[10] Rogier, G. and Velotti, P. (2018) Narcissistic Implications in Gambling Disorder: The Mediating Role of Emotion and Dysregulation. Journal of Gambling Studies, 34, 1241-1260. https://doi.org/10.1007/s10899-018-9759-x

[11] Laurence, K. (2016) The Addicted Narcissist. How Substance Addiction Contributes to Pathological Narcissism with Implications for Treatment. A Hermeneutic Literature Review. Dissertation, Auckland University of Technology, Department of Psychology, Auckland.

[12] Pritz, W.F. and Mitterauer, B. (1977) The Concept of Narcissism and Organismic Self-Reference. International Review of Psycho-Analysis, 4, 181-116.

[13] Mitterauer, B. (2003) Das Prinzip des Narzissmus-Modell der polyontologischen Selbstreferenz. Grundlagen aus Kybernetik und Geisteswissenschaft, 44, 82-87.

[14] Mitterauer, B. (2014) Basic Nature of Personalities Running Amok in Western Cultures. The Bi-Monthly Journal of the BWW Society, March-April Edition.

[15] Mitterauer, B. (2006) Pseudoomnipotence: A Model of the Manic Syndrome. In: Kotlar, M.B., Ed., New Developments in Mania Research, Nova Science Publishers, New York, 161-178.

[16] Mitterauer, B.J. (2009) Narziss und Echo. Ein psychobiologisches Modell der Depression. Springer, New York. https://doi.org/10.1007/978-3-211-99140-4

[17] Mitterauer, B. (2020) The Passion of Will in Schizophrenia: Towards a Philosophy of Mental Disorders. The Bi-Monthly Journal of the BWW Society, 20, 1-17.

http://www.bwwsociety.org/journal/current/2020/jul-aug/the-passion-of-will-in-sch izophrenia.htm

[18] Jung, C.G. (1976) Die Archetypen und das kollektive Unbewußte. Walter, Freiburg.

[19] Mitterauer, B.J. (2010) Many Realities: Outline of a Brain Philosophy Based on Glial-Neuronal Interactions. Journal of Intelligent Systems, 19, 337-362. https://doi.org/10.1515/JISYS.2010.19.4.337

[20] Maturana, H. (1970) Biology of Cognition. Biological Computer Laboratory. Report No. 9.0. University of Illinois, Urbana.

[21] Mitterauer, B.J. (2018) Astrocyte-Synapse Receptor Coupling in Tripartite Synapses: A Mechanism for Self Observing Robots. Advances in Bioscience and Biotechnology, 9, 63-82. https://doi.org/10.4236/abb.2018.92006

[22] Mitterauer, B. (2019) The Passion of Will in Depression: Towards a Philosophy of Mental Disorders. The Bi-Monthly Journal of the BWW Society, 19, 1-10.

https://bwwsociety.org/journal/current/2019/sep-oct/the-passion-of-will-in-depress ion.htm

[23] Unterwald, E. and Howells, R. (2009) Upregulation of Opioid Receptors. In: Dean, R., Bilsky, E.J. and Negus, S.S., Eds., Opioid Receptors and Antagonists, Humana Press, Totowa, 19-44. https://doi.org/10.1007/978-1-59745-197-0_2

[24] Di Samo, M., Di Pierro, R. and Madeddu, F. (2018) The Relevance of Narcissism: A Review of Current Studies. Clinical Neuropsychiatry: Journal of Treatment Evaluation, 15, 242-250.

[25] Jin, X.-T., Tucker, B.R. and Drenan, R.M. (2020) Nicotine Self-Administration Induces Plastic Changes to Nicotinic Receptors in Medial Habenula. eNeuro, 7, 1-12. https://doi.org/10.1523/ENEURO.0197-20.2020

[26] Andreassen, C., Palleson, S. and Griffiths, M. (2017) The Relationship between Addictive Use of Social Media, Narcissism, and Self-Esteem: Findings from a Large National Survey. Addictive Behaviors, 64, 287-293. 
https://doi.org/10.1016/j.addbeh.2016.03.006

[27] Casale, S. and Banchi, V. (2020) Narcissism and Problematic Social Media Use: A Systematic Literature Review. Addictive Behaviors Reports, 11, Article ID: 100252. https://doi.org/10.1016/j.abrep.2020.100252 